\title{
Argentina e Brasil: políticas exteriores comparadas depois da Guerra Fria
}

\author{
MIRIAM GOMES SARAIVA* \\ LAURA TEDESCO**
}

\section{Introdução}

O começo dos anos noventa trouxe importantes modificações que se refletiram sobre o comportamento externo da Argentina e do Brasil, introduzindo diferenças em políticas exteriores que haviam alcançado um significativo grau de coincidência durante a década anterior.

Durante os anos 1980, quando tiveram lugar os primeiros passos do processo de integração entre os dois países, existiam coincidências entre as linhas de ação de suas políticas externas. No decorrer dos governos de Raúl Alfonsín e José Sarney, ambos mantiveram os países com perfis semelhantes, orientados por um padrão mais autônomo de política externa. Ambos atuaram de forma conjunta frente a temas regionais como a participação em foros latino-americanos (Grupo de Cartagena, Apoio e Grupo do Rio) e a criação da Zona de Paz no Atlântico Sul; assim como mantiveram, da mesma forma, uma política nuclear autônoma. Compartilhavam, também, a vontade política de implementar um processo de integração regional.

A partir da década de noventa, as políticas externas argentina e brasileira experimentaram transformações com vistas à adaptação ao novo contexto internacional, mas as percepções da ordem internacional estruturada por estes países adquiriram diferenças que influíram marcadamente sobre seus esforços de inserção externa.

O objetivo deste artigo é analisar comparativamente as diferenças estabelecidas entre as linhas mais gerais das políticas externas da Argentina e do Brasil nos anos 90 orientadas para o espectro político mais global, com ênfase na

\footnotetext{
Rev. Bras. Polit. Int. 44 (2): 126-150 [2001]

* Doutora pela Universidad Complutense de Madrid. Professora e pesquisadora do Programa de PósGraduação em História da Universidade do Estado do Rio de Janeiro.

** PhD, Warwick University. Professora de Ciência Política da School of Development Studies, University of East Anglia, Inglaterra.
} 
percepção de cada um desses países sobre a nova ordem internacional. ${ }^{1}$ Neste marco ressaltaremos as relações com os Estados Unidos, as questões de segurança e as relações regionais.

Com tais propósitos, o artigo está dividido em três partes. A primeira parte analisa as mudanças no cenário internacional que influenciaram as políticas externas argentina e brasileira. A Segunda discute o caso argentino, dando destaque inicialmente à crise doméstica e sua influência no desenho da política exterior. Em seguida, analisa as mudanças nessa política, especialmente nas relações com os Estados Unidos e nas questões de segurança, e examina as relações regionais.

A terceira parte está dedicada à política externa brasileira. Como a anterior, inicia com os fatores internos que incidiram sobre a política exterior do período, passando em seguida para a visão brasileira da ordem internacional e da inserção externa do país, para as relações com os Estados Unidos e alguns exemplos do comportamento externo brasileiro. Encerra com a análise das relações do Brasil com o entorno regional.

As conclusões comparam os dois casos em estudo. A ênfase está posta na percepção dos agentes formuladores da política exterior no que se refere à inserção internacional e ao processo de integração regional.

\section{O colapso da Guerra Fria}

A ordem internacional durante a Guerra Fria era de caráter bipolar, mas existiam de fato três mundos diferenciados: o primeiro mundo, capitalista e desenvolvido; o segundo, comunista e relativamente desenvolvido; e o terceiro mundo, subdesenvolvido. O primeiro combinava inclusão econômica -a maioria da população participava ativamente da vida econômica do país - individualismo e democracia política. Com a queda dos sistemas comunistas de produção e dos regimes autoritários, os princípios de inclusão econômica, individualismo e democracia política foram adotados pela grande maioria dos países (Dahrendorf, 1996).

O colapso da Guerra Fria foi resultado de um processo histórico que começou em 1971, quando o então presidente Richard Nixon, com a finalidade de incrementar a liberdade de ação econômica e política, suspendeu a convertibilidade do dólar, destruindo o já questionado sistema de Bretton Woods. Esta medida pode ser, por seu turno, considerada como o ponto de partida do processo de globalização do capital. Finalmente, em 1973 o sistema de Bretton Woods caiu de vez com a decisão de se permitir a flutuação da taxa de câmbio. Estas medidas provocaram um crescente movimento de capitais que, junto ao avanço tecnológico dos anos 80 , originou o processo de globalização econômica. Neste contexto, o sistema soviético foi incapaz de seguir esta nova etapa de desenvolvimento (Chomsky, 1992). 
Esta superação definitiva da ordem bipolar da Guerra Fria com a decomposição súbita da União Soviética e a estruturação de uma nova ordem baseada, no campo político, na defesa de valores vinculados ao pluralismo democrático e, no econômico, nos preceitos da economia de mercado, abriu uma série de interrogações sobre a nova ordem e, particularmente, sobre o papel a ser exercido nela pelos Estados Unidos. Isto criou espaços para a estruturação de distintas percepções por parte de formuladores de política externa e incidiu nas mudanças que tiveram lugar nos comportamentos externos específicos da Argentina e do Brasil.

Na América Latina, em geral, estas transformações da ordem internacional, combinadas com problemas internos, tiveram impacto sobre as políticas externas dos países da região. ${ }^{2}$ Até o final dos anos 80 , estes conviviam com problemas resultantes da crise da dívida externa, do esgotamento dos modelos econômicos anteriores e das dificuldades de inserção na economia internacional. Assim, o comportamento externo de corte mais autonomista seguido anteriormente por estes países foi substituído por visões mais pragmáticas vinculadas aos padrões neoliberais que pautaram a reorganização do cenário internacional dos anos 90, e assumidos por novos governos nacionais.

Em relação aos processos de integração regional, houve um período de avanços. Na economia globalizada, os estímulos e pressões para a abertura econômica dos países, uma menor intervenção governamental na economia, assim como a desregulamentação de diversas facetas das economias e equilíbrio fiscal passaram a ser freqüentes para os países de menor desenvolvimento. A noção de economia de mercado veio acompanhada de uma internacionalização crescente dos circuitos produtivos e da transnacionalização dos movimentos de capitais e dos investimentos (Schirm, 1996).

Neste contexto, o novo modelo de integração adaptado ao padrão econômico neoliberal foi considerado, inicialmente, como uma forma de aumentar a competitividade econômica e de enfrentar desafios e pressões internas e externas resultantes da economia globalizada. Assim, com a passagem de década, houve um novo impulso no processo de integração Centro-Americano e no Pacto Andino, orientado para o estabelecimento de uma união aduaneira, e formou-se o Mercosul, com o mesmo propósito. Estes grupos, ao contrário do modelo de integração cepalino, caracterizaram-se por sua abertura para o exterior com a liberalização das economias e, ao mesmo tempo, buscaram tornar-se mais atrativos para o capital estrangeiro. A opção por um processo de integração de caráter aberto e funcionando como canal de inserção na economia internacional converteu-se em um mecanismo importante no arco das ações externas. ${ }^{3}$ 


\section{Argentina: uma política exterior em movimento}

\section{Redefinindo a política externa}

Entre 1983 e 1989, o governo de Raúl Alfonsín experimentou o fim de uma longa crise do Estado argentino. ${ }^{4}$ Este período foi marcado pela recriação das coalizões políticas e de classe, enquanto distintas facções lutavam para manter ou modificar sua cota de poder. Neste jogo de poder, as relações sociais foram profundamente modificadas. O resultado destas mudanças nas relações sociais trouxe consigo um forte questionamento do Estado. O primeiro governo de Carlos Menem, percebendo a situação como uma crise de dominação, implementou uma série de reformas do Estado com o objetivo de reestruturar seu poder de dominação. Assim, nos primeiros anos da década de 90, existiu uma redefinição de alianças políticas e econômicas tanto a nível doméstico quanto a nível internacional, posto que a Argentina não foi alheia à reconsideração das alianças internacionais que se originaram com o desmembramento da União Soviética. No marco das reformulações, a política externa, sendo vista como, em parte, responsável pelos fracassos econômicos do passado, foi questionada dentro de um processo de revisionismo mais geral do modelo - confrontativo - de inserção externa adotado historicamente pelo país.

Neste contexto, a política externa foi utilizada como um instrumento para estabelecer ou consolidar alianças internacionais que ajudaram a redesenhar e/ou manter as novas relações sociais domésticas. O primeiro chanceler de Carlos Menem foi Domingo Cavallo, um economista que abraçou o conceito de "Estado comercial" (trading state) de Rosecrance (1986). As transformações do cenário internacional foram cruciais para delinear as percepções de Cavallo. A política exterior foi vista como um instrumento para redesenhar o Estado seguindo as novas tendências da ordem mundial.

O primeiro governo de Menem estabeleceu um Estado neoliberal. Este tipo de Estado domina através da imagem de um Estado guardião da democracia, da lei, da eficiência, e como provedor do marco legal adequado para o desenvolvimento dos mercados, da sociedade civil e do indivíduo. Um dos objetivos cruciais do Estado neoliberal é a liberalização da economia com o fim de atrair capitais estrangeiros. Para isso, o país deve ser considerado como um sócio confiável e previsível. A política externa argentina teve, assim, esta missão. O restabelecimento de relações diplomáticas com o Reino Unido, por exemplo, foi considerado como condição essencial para o estabelecimento de uma nova relação com os Estados Unidos, entendida esta como o elemento chave para se alcançar estabilidade e crescimento econômico. Neste contexto, os conceitos de interesse nacional e soberania foram redefinidos de acordo com suas relações com o desenvolvimento econômico doméstico e a integração com a economia internacional. 
Em resposta à profunda crise doméstica, as mudanças foram dramaticamente implementadas. A famosa frase do Chanceler Guido Di Tella (1991-1999) sobre o estabelecimento de "relaciones carnales" com os Estados Unidos foi parte desta estratégia de mudanças abruptas. Esta consistia em estabelecer medidas ou expressar idéias de grande impacto que pudessem ajudar a estabilizar a economia. Como a Argentina não tinha ameaças externas, os decisores de política exterior perceberam que o interesse nacional, no contexto da pior crise econômica até então experimentada, devia estar ligado à saída desta crise. As mudanças na política externa estiveram, então, profundamente relacionadas com a economia doméstica, e seu objetivo principal foi facilitar o crescimento econômico. $\mathrm{O}$ argumento principal, neste quadro, foi o reconhecimento dos Estados Unidos como líder regional e internacional. Portanto, a Argentina deveria estabelecer uma boa relação com este país, na medida em que esta relação não prejudicasse interesses materiais da Argentina (Escudé e Fontana, 1998:54).

Esta nova percepção da estratégia externa argentina encontrou aceitação na diplomacia. ${ }^{5}$ A lógica de formulação de política externa concentra-se sobretudo no vínculo entre a presidência e a cúpula da Chancelaria, integrada basicamente por funcionários de origem política, enquanto o corpo diplomático de carreira fica mais afastado deste núcleo. ${ }^{6}$ Isto contribuiu para que a Chancelaria tenha sido permeável às novas idéias gestadas na arena política.

A política externa de Menem foi teoricamente analisada por Carlos Escudé (1995). ${ }^{7}$ Em sua análise, Escudé define diferentes tipos de racionalidades no processo de tomada de decisões: cidadano-cêntricas, estado-cêntricas, governocêntricas, elite-cêntricas ou estadistas-cêntricas. Estas distintas racionalidades definem-se pelos "diversos sujetos a los que una política exterior puede servir" (Escudé, 1995:32). Escudé argumenta que a lógica da política exterior de Menem sustentava-se numa nova hierarquia na qual a geração de recursos econômicos era mais importante que a geração de recursos político-militares (1995:97). Sugere que a política exterior menemista foi uma combinação de dois tipos de idéias relacionados à idéia do trading state de Rosecrance (1995:171).

No entanto, acreditamos que uma combinação entre a racionalidade elitecêntrica e a estado-cêntrica poderia nos ajudar a entender melhor esta política. Se a política exterior é um instrumento da política econômica, é possível analisar a racionalidade da primeira com base nos resultados da última. A Argentina tem, depois das reformas dos anos 90, uma pior distribuição de renda que em 1980. O incremento da desigualdade demonstra-se através da análise do coeficiente Gini que passou de 0.365 em 1980 a 0.412 em 1985; 0,443 em 1994; e 0,459 em 1997 (Tedesco, 2000). Enquanto o crescimento do PIB foi de 11.6\% de 1993 a 1998; no mesmo período, $80 \%$ dos salários industriais diminuíram em 23.1\% (Tedesco, 2000). Se os salários baixavam enquanto crescia a produtividade, a taxa de lucro absoluta também crescia, o que produz um forte impacto na distribuição de renda e ajuda a 
entender a evolução do coeficiente Gini. Uma estratégia econômica definida, por conta de seus resultados, como elite-cêntrica (parafraseando Escudé "por los sujetos a los que tiende a servir") produzirá, provavelmente, uma política exterior iluminada pela mesma racionalidade que sustentaria a dinâmica da política econômica.

\section{Da teoria à prática}

A nova política externa baseava-se em duas idéias: realismo e pragmatismo. O primeiro princípio que a alentava era que a ordem internacional devia ser entendida como realmente era, mais que como deveria ser. Isto significava aceitar o lugar marginal da Argentina nesta ordem. E, ademais, implicava no estabelecimento de uma nova relação com os Estados Unidos baseada na forma na qual a ordem internacional se apresentava na realidade.

O primeiro passo da política foi o restabelecimento de relações diplomáticas com o Reino Unido. Isto foi visto como uma medida que melhoraria as relações com os Estados Unidos, a União Européia e, em termos mais gerais, a imagem internacional do país. Guido Di Tella apresentava as mudanças como uma continuação da grande transformação da Argentina em um país democrático e economicamente estável.

As mudanças eram, assim mesmo, resultado da reconceitualização da idéia de soberania e interesse nacional. De acordo com Di Tella, a essência do interesse nacional era sustentar os princípios democráticos, "defender el derecho al bienestar de los pueblos, sin arriesgar el valor más importante, que reside en lo que hace al bienestar" (Clarín, 12/11/91:13). Portanto, o conceito de interesse nacional estava relacionado ao bem-estar do povo. A idéia da soberania também foi relacionada com o desenvolvimento econômico. Um país, argumentava-se, somente poderia ser soberano se fosse desenvolvido. Neste sentido, a política externa era entendida como um braço da política econômica cujo principal objetivo era criar uma imagem da Argentina como um país confiável e previsível, ou seja, um "país normal". ${ }^{8}$. Tulchin (1998:164) capturou esta idéia ao assinalar que "foreign policy has come to be understood as a reflection of how the nation sees itself and how it wishes to be seen, as well as an instrument for national development".

Neste novo marco, o restabelecimento de relações diplomáticas com o Reino Unido era considerado muito mais importante que a disputa pela soberania das Ilhas Malvinas/Falklands. ${ }^{9}$ O resultado final desta política de cooperação foi o restabelecimento de viagens aéreas com as Ilhas em 1999. Esta medida foi provocada, em parte, pela detenção de Augusto Pinochet em Londres em outubro de 1998, mas é impossível ignorar o papel que jogaram os oito anos de relações diplomáticas para melhorar as relações em geral. 
O tema mais importante, como já assinalamos, foi a relação com os Estados Unidos. Certamente, as mudanças efetuadas estavam vinculadas a este relacionamento, e basearam-se em "três percepções: o papel unipolar por eles exercido ao término da Guerra Fria, sua capacidade de influência nos órgãos multilaterais, e a capacidade de consumo de seu mercado e a disponibilidade de capitais para investimentos externos" (Cervo, 2000b:p.45). A nova política externa substituía a confrontação pela cooperação.

Dentro desta perspectiva, uma das primeiras medidas foi modificar os votos da Argentina nas Nações Unidas com vistas a conseguir maior coincidência com os votos norte-americanos. Ademais, Argentina começou a dar maior importância a temas estratégicos como o futuro do míssil Cóndor II e o plano nuclear. Em setembro de 1989, o recém-empossado presidente Carlos Menem viajou aos Estados Unidos com uma agenda que incluía o desmantelamento do míssel que havia sido financiado pelo Egito e pelo Iraque em 1984. O governo norte-americano exigia a sua destruição.

O desmantelamento do míssel, porém, produziu discrepâncias no Gabinete Nacional. Enquanto Domingo Cavallo, desde a Chancelaria, insistia que o desmantelamento era crucial para melhorar as relações com os Estados Unidos, Humberto Romero, desde o Ministério da Defesa, sustentava que o governo devia afirmar que somente utilizaria a tecnologia para fins pacíficos, o que permitira continuar seu desenvolvimento. O Brasil era um exemplo a seguir, argumentavase especialmente nos meios de comunicação, já que mantinha, por seu turno, boas relações diplomáticas com os Estados Unidos independentemente de sua política nuclear, de sua indústria de armamentos e de seu desenvolvimento missilístico (Ámbito Financiero, 27/4/90:11). Logo depois da mudança no Gabinete em abril de 1991, Di Tella manteve a posição de Cavallo e em maio deste mesmo ano foi anunciado que o míssel seria desmantelado e que o país se integraria ao Regime de Controle de Tecnologias Missilísticas (MTCR).

Em relação à política nuclear, o governo considerava que mudando-a, também seriam beneficiadas as relações regionais. O presidente Menem deu continuidade ao processo de integração com o Brasil iniciado em 1985 e prestou especial interesse à política de cooperação em matéria nuclear. A partir dos anos 90 os dois países conjuntamente abriram mão de suas políticas nucleares autônomas. Depois de mais de duas décadas de resistência ao instrumento de não-proliferação nuclear; ambos ratificaram o Tratado de Tlatelolco e assinaram o Tratado de NãoProliferação (TNP) de armas nucleares. Esta integração de suas políticas nucleares, coordenadas com uma aceitação das disposições internacionais dominantes sobre o tema, contribuiu para que os dois países aparecessem como parceiros mais confiáveis frente aos Estados Unidos e à União Européia.

Estas mudanças foram possíveis, internamente, pela desmobilização política das Forças Armadas depois da queda da ditadura militar. Em princípio dos anos 90, 
os militares estavam sob controle civil, o que explica, em parte, o êxito do presidente Menem em modificar a política exterior e os temas estratégicos que, historicamente, haviam estado abaixo da esfera militar.

Durante o período o feito mais controvertido foi, sem dúvida a participação argentina na Guerra do Golfo. O presidente Menem decidiu enviar os navios de guerra sem consultar previamente o Congresso e os países vizinhos. O Chanceler Cavallo argumentou que esta decisão ajudaria a integração da economia argentina no mundo, incrementaria os níveis de investimento estrangeiro e, portanto, significava uma continuidade das reformas econômicas domésticas (Clarín, 19/9/90:5). Neste caso, a política externa aparecia, novamente, atada à estratégia econômica.

A participação na guerra provocou um importante debate interno. A União Cívica Radical, desde a oposição, defendia que o fim da Guerra Fria não havia significado o fim do conflito Norte-Sul. Neste conflito, a Argentina formava parte do Sul e, portanto, devia identificar-se com os interesses deste grupo de países. Segundo seus argumentos, a Argentina deveria coordenar sua política exterior com estes países, especialmente com os de sua região. O radicalismo sustentava que o país deveria condenar a invasão do Kuwait e aderir ao embargo imposto pelas Nações Unidas.

Nesta questão, a diferença mais importante entre Peronistas e Radicais era a conceitualização do interesse nacional. O governo considerava que o interesse nacional era uma aliança com países do Primeiro Mundo através da qual a crise econômica poderia ser superada. O Partido Radical considerava que o interesse nacional da Argentina se definia por consolidar uma aliança com os países em desenvolvimento (em continuidade à política externa do governo radical anterior). Esta aliança permitir-lhe-ia integrar-se à economia global.

Em termos gerais, o fato abriu caminho para uma nova política de segurança mais geral, marcada pela aproximação com os norte-americanos. Durante o período, somada à política nuclear e de desarmamento, a Argentina participou de um grande número de Operações de Paz das Nações Unidas e tornou-se aliada, extra-Otan, dos Estados Unidos.

Outro debate foi gerado com a decisão de se abandonar o Movimento dos Não-Alinhados em outubro de 1991. O governo argumentou que o Movimento não havia mudado, apesar das transformações no sistema internacional com o fim da Guerra Fria, e Di Tella sintetizou a posição expressando que "el interés que impone la cooperación con los países de quienes depende nuestro bienestar converge con la defensa de nuestros principios" ( La Nación, 4/11/91:7).

Também a questão das relações com Cuba e a posição no que diz respeito ao conflito no Haití ajudaram a configurar a nova política exterior. Em março de 1991 a posição argentina frente a Cuba modificou-se. Nas Nações Unidas, a Argentina votou, junto aos Estados Unidos e países europeus, a favor de uma resolução que propunha o envio de uma Comissão com vistas a investigar a situação 
dos direitos humanos na Ilha. O presidente Menem se reuniu em distintas oportunidades com o lobby anti-castrista de Miami e sustentou que Cuba deveria mudar sua ideologia para terminar seu isolamento do resto da América Latina. O tema cubano foi discutido em várias ocasiões em Cúpulas Ibero-Americanas e no Grupo do Rio. Nestes foros, o governo argentino enfrentou-se com o mexicano, que rechaçava a consideração do tema por identificá-lo como uma violação ao princípio da não-intervenção. O governo argentino também divergiu inicialmente da posição brasileira quando, em 1994, o então presidente Itamar Franco propôs a entrada de Cuba na Organização dos Estados Americanos (OEA). Em linhas gerais, a maioria dos países latino-americanos seguia a posição do Brasil e do México, com exceção do Chile, cuja postura era bastante próxima à argentina.

O golpe militar no Haití, em 1991, foi um teste para a reação regional em defesa da democracia. Depois de muitas discussões sobre o princípio da nãointervenção, o caso ficou esquecido por dois anos. Em outubro de 1993, o governo norte-americano, junto com o Conselho de Segurança das Nações Unidas, decretou um embargo naval ao Haiti com vistas a pressionar o governo militar para a implementação dos acordos de Julho que consideravam o retorno à democracia. A Argentina decidiu enviar navios de guerra e, com a passagem do tempo, foi aproximando-se cada vez mais de um apoio à posição norte-americana sobre uma intervenção militar. Venezuela, Uruguai, Jamaica, Paraguai, Colômbia, Nicarágua e México opunham-se a uma intervenção militar. O Brasil, como país membro do Conselho de Segurança, se absteve.

A atitude do governo argentino frente a estes dois temas regionais deve ser entendida nos marcos mais amplos das novas relações com os Estados Unidos. Este relacionamento significava, nos planos internacional e regional, uma reconsideração das alianças baseada na reconceitualização do interesse nacional que, de acordo com o chanceler Di Tella, significava a cooperação com os países mais desenvolvidos na medida em que deles dependia o bem-estar econômico da Argentina.

\section{O marco regional}

No tocante às alianças regionais, o governo aprofundou as relações com o Brasil especialmente através da assinatura do Tratado de Assunção e criação do Mercosul. O Tratado previa uma tarifa zero a partir de 1995. Esta foi uma política que teve consenso entre os partidos políticos, embora tenha tido que passar por períodos de pouca popularidade, especialmente em situações onde o déficit comercial com Brasil se fez sentir; por exemplo, em 1992. Neste período, argumentos protecionistas adquiriram força especialmente na União Industrial Argentina (UIA), assim como rumores, provindos de outros setores empresariais, que incentivavam 
a abandonar o Mercosul para integrar-se à Área de Livre Comércio da América do Norte (Nafta). Esta dicotomia Nafta/Mercosul esteve presente no discurso do governo durante os primeiros anos da década de noventa. Desde a imprensa argentina, se acusava o Brasil de manter uma atitude protecionista frente à liberalização da economia argentina. O Brasil era considerado o poder hegemônico cuja autonomia crescia graças ao Mercosul, enquanto a Argentina incrementava a sua dependência. ${ }^{10}$ Apesar dessas dúvidas acerca de suas limitações e possibilidades, o Mercosul significou uma das grandes transformações do período: o tradicional adversário convertia-se no maior sócio comercial colocando-se, de fato, como aliado no campo. ${ }^{11}$

Em um marco de negociações e de alternância entre momentos de avanço e momentos de estagnação, da assinatura do Tratado de Assunção até o final da década, o comércio entre ambos teve um crescimento significativo. ${ }^{12}$ Mas este crescimento não veio acompanhado de uma articulação no campo industrial e cambial, e a desvalorização do real em 1999, em contraste com a convertibilidade da moeda argentina, teve um impacto negativo sobre o comércio entre ambos.

Este fortalecimento no campo comercial não significou, porém, uma aliança política no âmbito internacional. Nesta área, os Estados Unidos seguiram como referência principal.

Dentro deste contexto, alguns passos no sentido da segurança entre ambos foram implementados pelo governo menemista, com especial atenção à política nuclear. Em novembro de 1990, Argentina e Brasil firmaram uma Declaração Conjunta para uma Política Nuclear Comum, que foi o ponto de partida de uma série de acordos bilaterais. Ambos países acordaram em usar energia nuclear somente com objetivos pacíficos, em ratificar o Tratado de Tlatelolco e em solicitar conjuntamente à Comissão Internacional de Energia Atômica o controle do uso pacífico da energia nuclear (Tulchin, 1998:185). A Argentina ratificou Tlatelolco junto com o Brasil em 1994, e aderiu ao Tratado de Não Proliferação pouco depois (em 1997, o Brasil também aderiu ao Tratado). Ambos os países criaram o Mecanismo de Consulta sobre Defesa e Segurança Argentino-Brasileiro junto com uma agência bilateral para administrar o sistema (Abacc).

Ademais, em setembro de 1996, pela primeira vez os exércitos de ambos os países realizaram um exercício conjunto na província de Corrientes. O Brasil fez pública sua política de defesa onde eliminavam-se as hipóteses de conflito com a Argentina. Finalmente, as armadas também participaram de forma conjunta em exercícios tais como o Operativo Camas, Araex, Fraterno e Atlasul (Escudé e Fontana, 1998:61), além de estruturarem o Mecanismo de Consulta sobre Defesa e Segurança Argentino-Brasileiro. No entanto, isto não significou a formação de uma política de defesa comum, mantendo-se a Argentina uma inserção diferente nos marcos da segurança internacional. 
Outro rival tradicional, o Chile, também transformou-se em sócio comercial. Mas em termos gerais, a relação com o Chile esteve, em parte, concentrada na carreira armamentista. As Forças Armadas de ambos países seguiam utilizando o discurso sobre o suposto poderio militar do país vizinho para justificar a aquisição de novos armamentos. Para os militares argentinos, a maior preocupação era o míssil El Rayo, que não havia sido desmantelado como o Cóndor II. ${ }^{13}$ No entanto, os argumentos das Forças Armadas foram, finalmente, neutralizados. E, neste terreno, a Argentina foi um caso excepcional. Em seguida à transição democrática, os governos argentinos conseguiram diminuir o poder político e econômico das Forças Armadas. O gasto militar como porcentagem do PIB era 3.8\% em 1985, 3.5\% em 1989, e 1.9\% em 1991 (Escudé e Fontana, 1998:63). Outras medidas, como a abolição do serviço militar obrigatório e o desmantelamento do míssel Condor, reforçam este argumento. Entretanto, esta situação não poderia ser sustentada em relação ao Brasil ou Chile. Enquanto o gasto militar foi apenas 1,9\% do PIB na Argentina em 1991, no Chile alcançou 3,4\% no mesmo ano. O contingente militar alcançava o número de 75.000 na Argentina, 93.000 no Chile e 300.000 no Brasil (Escudé e Fontana, 1998:63).

Porém, e apesar destas diferenças, ninguém pode duvidar que o cenário mudou drasticamente no Cone Sul. Na Argentina, a desmobilização política das Forças Armadas começou nos anos oitenta a partir da derrota no conflito pelas ilhas Malvinas. O processo de democratização, junto com as políticas de Raúl Alfonsín com respeito às violações aos direitos humanos, minou ainda mais o papel das Forças Armadas. O movimento carapintada, ${ }^{14}$ apesar de Ter, a curto prazo, parecido dar poder às Forças Armadas, no longo prazo erodiu ainda mais o papel político dos militares.

\section{O caso brasileiro: redefinição da política externa}

No caso brasileiro, as modificações ocorridas no cenário internacional vieram acompanhadas de mudanças de ordem doméstica que impactaram sobre a política externa. Durante o período, o Brasil experimentou uma situação diferente da Argentina. Enquanto esta manteve uma regularidade em função da longevidade do governo Menem, a política doméstica brasileira foi menos contínua, com três presidentes distintos que, com características diferentes, não deram seqüência a um mesmo projeto. No campo da política externa, o avanço da globalização, que levou ao esvaziamento definitivo do eixo Norte/Sul da política internacional, trouxe restrições ao projeto nacional de política exterior que vinha sendo seguido anteriormente e abriu espaço para novas reflexões e formulações sobre o comportamento brasileiro vis a vis o exterior. 


\section{Política interna, estratégia de desenvolvimento e o papel do Itamaraty}

Internamente, o final da década de 80 foi marcado pela consolidação do processo de democratização e pela crise econômica resultante de uma crise do modelo de desenvolvimento adotado há muito tempo. O esgotamento do modelo de crescimento baseado na dinâmica da substituição das importações, junto com os problemas financeiros resultantes da crise da dívida externa, já era perceptível nos anos 80. O Brasil entra nos anos 90 com uma confrontação entre um pensamento liberal e outro nacionalista sobre os rumos da estratégia de desenvolvimento a ser adotada. A ascensão de Collor de Mello, de corte liberal, à presidência em 1990, favoreceu um processo de abertura da economia com vistas a um crescimento da produção articulado com os mercados externos como estímulo à renovação do parque produtivo e como garantia de uma inserção mais competitiva na economia internacional. Mas estes esforços de reformulação do modelo de desenvolvimento a partir da abertura econômica tiveram menos êxito que no caso argentino. No Brasil, enfrentaram problemas e resistências internas, assim como dificuldades na gestão presidencial que levaram ao impeachment do presidente ao final de 1992.

O impeachment de Collor e a ascensão de Itamar Franco à presidência comprometeram, por um tempo, o pensamento mais liberal na política brasileira. $\mathrm{O}$ corte mais nacionalista de Franco que, rapidamente, deu sinais de que não manteria igualmente o processo de abertura da economia, trouxe alterações internas e impactou sobre a política externa. A reforma estrutural da economia seguiu, mas de forma mais incerta, com avanços e recuos, entre posturas de resistência ao ajuste aberturista por parte de setores do empresariado nacional e de esforços do governo em implementar o programa. A indefinição da estratégia de desenvolvimento a ser adotada, que não se situava no espectro da substituição de importações, mas tampouco tratava-se exatamente da ideologia econômica do neoliberalismo, dificultou a formulação do comportamento externo.

O lançamento do Plano Real, em meados de 1994 e a eleição de Fernando Henrique Cardoso reorientaram os esforços do governo no sentido das reformas aberturistas e deram mais credibilidade ao país no exterior. A nova coalizão de governo expressou um maior consenso interno -entre as elites políticas e empresariais- em torno às reformas econômicas e estatais, mas conviveu ainda com certa tensão entre uma vertente mais reticente ao processo de adaptação às mudanças internacionais (propensa a uma consideração caso a caso), e outra mais definidamente neoliberal.

Uma questão importante no caso brasileiro é a participação intensa e tradicional da corporação diplomática no processo de formulação da política externa. Por muito tempo, a política externa era vista como área de especialistas, não sendo objeto de interesse por parte da maioria dos políticos e da sociedade brasileira em geral. O longo período de governo autoritário, onde o Itamaraty pode exercer um 
papel importante no processo decisório, distanciou ainda mais outras dimensões políticas dos temas externos, deixando a chancelaria acima de questões políticoeleitorais (Lima, 2000).

O processo de democratização da vida política trouxe à tona esta questão, mas não resolveu as difíceis relações entre a política e a diplomacia, nem conseguiu levar a bom termo um diálogo entre a chancelaria e setores importantes do empresariado nacional e da sociedade civil. ${ }^{15}$ Esta centralização da formulação de política externa, se tradicionalmente contribuiu para um comportamento mais estável, em termos gerais, apesar de mudanças ocorridas no quadro político, criou certas dificuldades de renovação e de adaptação à nova realidade nacional (democratização e abertura econômica) e internacional. Contribuiu, assim, para que a diplomacia enfrentasse dificuldades em negociações ou em representar distintos interesses sociais, e fez com que a inflexão experimentada pela política externa brasileira fosse mais lenta, com avanços e recuos.

As diferenças na percepção da ordem internacional, as relações com os Estados Unidos e as questões de segurança

Conforme já foi visto, o início do governo Menem trouxe uma mudança de rumo importante na política externa argentina. Para a nova administração, colocavase como fundamental romper a tradição de desafio aos Estados Unidos e buscar uma aliança efetiva com o parceiro do norte em relação a temas gerais da política internacional como forma de garantir recursos para o projeto econômico interno e para uma inserção internacional mais ativa junto e próxima ao diretório dos grandes. A diplomacia brasileira, por seu turno, pôs em xeque o paradigma que regia a política exterior do país desde os anos 70 e buscou redefinições, agregando aos conceitos tradicionais da atuação externa brasileira novas categorias de interpretação da realidade internacional. ${ }^{16}$

Com a ascensão de Collor, as linhas gerais que nortearam o comportamento externo brasileiro durante muitos anos foram questionadas, abrindo-se o que poderia qualificar-se de crise de paradigma da política externa. ${ }^{17}$ Com a conjugação de fatores externos e internos, as premissas vinculadas ao desenvolvimentismo, que já vinham perdendo seu dinamismo, foram definitivamente superadas, e o consenso que existia internamente nas elites sobre o projeto de política externa se rompeu.

Durante esta administração, as linhas gerais baseadas no paradigma globalista que nortearam o comportamento externo brasileiro durante muitos anos deram lugar a uma percepção que sustentava que abandonando as queixas em relação à economia internacional e aproximando-se dos Estados Unidos, o Brasil poderia colocar-se como interlocutor válido no cenário internacional. Assim, o governo se propôs a modificar o perfil internacional do país atualizando a agenda de acordo com os novos temas, construindo uma melhor relação com os Estados 
Unidos e desfazendo o perfil terceiro-mundista do Brasil. Buscava uma inserção externa mais competitiva que aproximasse o país do Primeiro Mundo (Abdenur, 1994).

Entretanto, o governo procurou manter, em continuidade com os traços mais perduráveis da política externa brasileira, o caráter vinculante da mesma com o modelo de desenvolvimento, orientada então para suscitar o respaldo externo às reformas econômicas nacionais.

Estas modificações introduzidas pelo governo Collor, contribuíram para o surgimento de diferenças dentro da diplomacia brasileira. Esta, que historicamente teve uma forte influência sobre a formulação da política exterior mantendo uma aparência de coesão em termos de idéias, encontrou sua autonomia na formulação da política limitada.

As linhas de política externa definidas pelo governo Collor foram de difícil implementação devido aos problemas na gestão do plano econômico e pela crise de governabilidade que atravessou Brasil (Lima e Hirst, 1994:58). Um dos poucos exemplos positivos foi a Conferência do Meio Ambiente, de 1992 no Rio de Janeiro, com vistas, entre outras, à acumulação de um capital diplomático para o país.

O fim prematuro do governo de Collor e o questionamento do pensamento neoliberal que isto acarretou, tornaram ainda mais complicada a construção de consenso em política exterior. A interrupção do ajuste estrutural da economia limitou as reformas ao âmbito do comércio exterior, no sentido de uma maior abertura relativa, e trouxe debates.

A ascensão de Itamar Franco à presidência teve impacto na política externa pois esta recuperou em parte a preponderância de seus pressupostos anteriores dando um fôlego maior à vertente mais desenvolvimentista. Abre assim um fosso em relação ao comportamento da Argentina frente aos Estados Unidos.

Neste período, a visão da Chancelaria da ordem internacional pautou-se na existência de um cenário de "polaridades indefinidas," onde não estava prédefinido o lugar que cada um dos principais atores viria a ocupar (Lafer e Fonseca Jr, 1994). A diplomacia brasileira estava ainda assimilando o processo de globalização, e a ordem internacional era vista como transitória e instável. ${ }^{18}$

As premissas principais da política externa brasileira deste período se baseiam em um paradigma globalista, em um projeto de inserção externa de um país continental em um cenário internacional descontínuo, com interesses na dinâmica de globalização da economia mundial, e como parceiro importante no processo de regionalização da América Latina e do Norte. Assim, o Brasil atuou mais ativamente nos foros multilaterais; aprofundou a integração regional com destaque para o Mercosul; buscou a aproximação com novos parceiros externos como a Índia e a China (Hirst e Pinheiro, 1995:11). No que diz respeito aos Estados Unidos, embora a diplomacia brasileira tenha buscado "desdramatizar" as relações evitando tanto alianças incondicionais quanto enfrentamento, o recuo no 
processo da abertura da economia desestabilizou as relações, e as coincidências diminuíram. ${ }^{19}$

O início do governo Fernando Henrique Cardoso reviveu os padrões que haviam se delineado no governo Collor. A inflexão mais relevante foi a aceitação de um novo conceito de "soberania compartilhada", diferente do conceito clássico de soberania (Silva, 1999). Isto se baseava em um mundo marcado por valores universais, onde os Estados estariam sujeitos às normas oriundas dos regimes internacionais. Da perspectiva da diplomacia brasileira, isto significa modificações no conceito de autonomia - a idéia da "autonomia pela integração", em detrimento de uma autonomia que visasse o isolamento ou a auto-suficiência. ${ }^{20}$ Esta modificação refletia um esforço da diplomacia brasileira de combinar, ao mesmo tempo, o caráter mais autônomo de orientação multilateral assumido tradicionalmente pela política externa com as características no novo contexto internacional. ${ }^{21}$

$\mathrm{O}$ argumento da diplomacia argentina da necessidade de aliar-se aos Estados Unidos incondicionalmente é substituído no Brasil pela percepção de ser um país com mais recursos de poder, mas com uma relativa inércia para aplicá$10 .^{22}$

A meados dos anos 90, desde a percepção brasileira existiria um "concerto" homogêneo de defesa da democracia, direitos humanos, livre mercado, e a tendência à formação de regimes em sua defesa. Mas as condições de manutenção deste "concerto" dependeriam da grande adaptabilidade da liderança norte-americana às demandas das demais potências e, em Segunda instância, dos países médios e pequenos (Fonseca Jr., 1999:32). Este cenário abriria espaço para que Brasil -em busca de mecanismos para ampliar sua capacidade de atuação internacionalpudesse adotar uma posição que não significasse nem alinhamento automático e nem uma postura de free rider. Uma posição que se orientasse, em primeiro lugar, pela percepção de que a política de blocos da ordem bipolar seria substituída por alinhamentos variáveis de acordo com o tema em questão e, em segundo, pela adesão aos regimes internacionais referentes aos temas vigentes (Fonseca Jr., 1999:39).

Com base nesta perspectiva, no que diz respeito aos Estados Unidos, a política externa brasileira manteve, por um lado, divergências tanto em temas da organização do comércio internacional e do protecionismo dos países desenvolvidos quanto em temas relacionados ao processo de integração do continente americano. Enquanto os Estados Unidos mostravam mais pressa em concluir a Associação Americana de Livre Comércio (Alca), o Brasil preferia atrasar a conclusão dando ênfase às experiências subregionais como o Mercosul. A partir de uma coincidência de opiniões entre a maioria dos setores empresariais e a diplomacia brasileira, esta adotou uma postura reticente frente à idéia da Alca. Mas, por outro lado, não subsistiu o aspecto de enfrentamento que ocorreu durante as décadas anteriores. Ao contrário, a "desdramatização" já experimentada no governo de Franco 
contribuiu para abaixar o perfil das exigências brasileiras. Por sua vez, o sucesso do Plano Real atuou como fator de maior credibilidade do Brasil junto a seus parceiros do Norte.

Além do vínculo com os Estados Unidos, destacaram-se também as questões relacionadas ao Conselho de Segurança, à participação nas Operações de Paz das Nações Unidas e à política nuclear.

Em relação à candidatura brasileira ao Conselho de Segurança, diante da perspectiva de reforma deste, a diplomacia nacional buscou incluir a Brasil como membro permanente ${ }^{23}$. Durante o governo de Itamar Franco esta perspectiva foi recolocada com base na idéia de que o Brasil deveria ser um global player, com participação na formação das regras de convivência e valores de uma nova ordem internacional em formação. A candidatura brasileira explicava-se pela capacidade do país de participar e exercer influência sobre o processo de tomada de decisões em questões da política internacional.

$\mathrm{Na}$ presidência de F.H.Cardoso a persepctiva manteve-se, embora com ênfase menor. A defesa de uma reforma das Nações Unidas com vistas a proporcionar-lhe condições de ocupar um papel relevante na ordem internacional, assim como da candidatura brasileira ao Conselho, seguiram nos discursos de diplomatas e do presidente. ${ }^{24}$

As Operações de Paz das Nações Unidas são outro exemplo importante de diferenças com a Argentina. Esta inaugurou um período de divergências com o Brasil com sua decisão unilateral de participar da Guerra do Golfo enquanto o Brasil aumentava sua distância em relação aos Estados Unidos, ao não participarem do esforço de guerra. Desde a perspectiva brasileira, a diplomacia manteve um discreto discurso de defesa do princípio da não-intervenção, tendendo a considerar -como tradicionalmente- as medidas coercitivas como instrumento de última instância. Em sua declaração do voto de abstenção quanto ao envio de uma operação de paz ao Haiti, em 1994, a questão da soberania e da independência dos Estados foi ressaltada (Resenha, 7/12/1994:15). O compromisso brasileiro somente com as Operações de Paz que visassem unicamente a manutenção da paz atuou como obstáculo. Neste caso, as limitações da corporação diplomática de se automodificar tiveram influência nesta postura. Com base então nestas premissas, o Brasil resguardou suas atuações para Operações que guardavam maior convergência com os interesses do país; em 1993 o Brasil participava de 5 Operações que incluíam os casos de Angola e Moçambique. Da virada da década até 1997 a Argentina havia participado em quase o dobro de Operações que o Brasil e, em muitos casos, a posição assumida por ambos foi distinta dando o Brasil prioridade para a participação com observadores. ${ }^{25}$

Com o governo de Fernando Henrique Cardoso iniciou-se uma lenta revisão dos comportamentos tradicionais da política externa brasileira. Em relação às Operações de Paz, em 1999 o Brasil participou de uma de imposição da paz no 
Timor Leste. Neste mesmo ano, frente à crise dos Balcãs, a diplomacia adotou uma posição de apoio discreto às iniciativas contra a Iugoslávia.

No campo da defesa dos direitos humanos também houve uma mudança de comportamento, neste caso em relação a Cuba. A reincorporação de Cuba à Organização dos Estados Americanos era defendida incondicionalmente pela diplomacia brasileira desde o fim do governo militar. Surpreendentemente, em junho de 1998 o chanceler brasileiro afirmou que o país deveria democratizar-se antes de voltar à Organização. Suas declarações abriram uma crise entre os dois países, mas não tiveram muito impacto nos meios de comunicação e políticos domésticos (Jornal do Brasil, 12/6/98:7).

Outra dimensão da postura brasileira frente à segurança internacional diz respeito à política de não-proliferação nuclear e de armamentos. Nesta esfera, como já foi visto, o comportamento brasileiro foi convergente com o de seus principais parceiros externos, especialmente a Argentina. Os governos de Collor de Mello e Menem aprofundaram uma política de cooperação no campo nuclear. Junto com o governo argentino, Brasil vai desistindo de sua política nuclear autônoma, tão apreciada anteriormente por setores militares. Em 1994, o Brasil ratificou, por fim, o Tratado de Tlatelolco, e em 1997 assinou o de Não-Proliferação de Armas Nucleares. No que diz respeito à questão de armamentos, em 1995 efetivou-se a adesão brasileira ao MTCR. Esta modificação na posição brasileira em sua política nuclear e de armamentos se deu de forma coordenada com a aceitação mais geral das disposições internacionais dominantes sobre o tema.

\section{O Brasil e a dimensão regional}

O tema de integração regional ocupou um lugar de maior relevo na política externa brasileira durante a década, embora não tenha sido implementado de forma linear.. Durante o governo de Collor de Mello, e seguindo um impulso iniciado na gestão de José Sarney, as preocupações integracionistas se apresentaram de forma clara. Em 1991, com a assinatura do Tratado de Assunção, o Mercosul passou a ser um elemento fundamental para o comportamento externo do país. A coincidência na aplicação de políticas econômicas de corte mais liberal pelos governos de Collor e Menem - embora com menos êxito no caso brasileiro - contribuíram para a adoção do modelo de integração de novo tipo com abertura para o exterior. ${ }^{26}$

Do ponto de vista da diplomacia brasileira, uma união aduaneira parecia favorecer a articulação de um projeto de desenvolvimento ao contribuir, em geral, para uma economia de escala mais especializada, com maiores vantagens comparativas e maior eficiência na produção. Com relação à inserção econômica externa do país, o Mercosul - tratando-se de uma experiência de integração aberta - poderia contribuir para melhorar o comércio exterior e converter-se em pólo de atração de investimentos privados externos. 
O comércio com a Argentina, no primeiro momento, não apareceu como elemento principal em função da tendência do Brasil de posicionar-se como um global trader, com seu comércio exterior multilateralizado. No entanto, na prática terminou funcionando como um dos setores onde a integração avançou mais.

No que se refere às relações externas do Mercosul, o bloco desempenharia um papel fundamental nos diálogos com outros grupos de países. A atuação dos quatro ganhou espaço especialmente depois da assinatura do Protocolo de Ouro Preto, que lhe conferiu uma personalidade jurídica. ${ }^{27}$ Isto favoreceu a estratégia brasileira de maiores contatos com mercados desenvolvidos.

A presidência de Itamar Franco trouxe consigo uma percepção um pouco diferente sobre o tema. Partindo de uma visão mais nacionalista, apontava para um projeto de integração de caráter mais introspectivo, dando mais importância à formação de uma Área de Livre Comércio na América do Sul (Alcsa) que ao próprio Mercosul (Cervo, 1998). Este último poderia atuar como um instrumento capaz de proporcionar ao Brasil um melhor posicionamento regional, assim como atuar na esfera comercial como elemento capaz de abrir caminho para a formação de uma área de livre comércio na América do Sul.

Mas na prática, a integração nos marcos do Mercosul foi impondo-se (enquanto o projeto da Alcsa ficou em nível de discurso). Apesar de suas limitações, o Mercosul assumiu um papel importante na política externa brasileira, passando a ocupar um lugar de relevo na agenda. Também diversos setores econômicos internos foram se engajando no processo, outorgando-lhe maior consistência.

Entretanto, as assimetrias entre as economias dos sócios e as diferenças nas políticas cambiais de Brasil e Argentina obstacularizaram uma aproximação maior. Uma coordenação macroeconômica, importante para a consecução do projeto inicial, não foi considerada prioritária. A preservação de autonomia, no que tange as decisões internas de política econômica, era considerada mais relevante. O ritmo do processo também ficou subordinado a crises econômicas e planos de estabilização. ${ }^{28}$ Desta forma, com certo pragmatismo, a integração caminhou pelos setores onde encontrou menor resistência.

Com a aplicação do Plano Real de estabilização, em 1994, e o início da presidência de Cardoso, as diferenças em relação à abertura da economia e ao câmbio diminuíram, aproximando-os no campo macroeconômico. No entanto, mesmo com o êxito do Plano, continuaram no Brasil as divergências internas sobre a aplicação de uma nova estratégia de desenvolvimento, divergências que, por sua vez, tiveram grande impacto nas relações entre Brasil e Argentina. ${ }^{29}$ Apesar destas fricções, o processo de negociação da formação da Alca e o diálogo estabelecido com a União Européia desenvolveram-se nos marcos da integração regional. Embora a diplomacia argentina tenha dado preferência a uma aliança com os Estados Unidos no campo político-estratégico, em termos econômicos a aliança com o Brasil prevaleceu. 
Em termos políticos, a formação do Mercosul era vista como um instrumento de reforço da capacidade de negociação brasileira, proporcionando-lhe um maior peso na arena internacional. A complexidade assumida pelas relações internacionais apontava à importância de se coordenar suas ações com outros parceiros. Deste modo, tornou-se importante para o Brasil trabalhar a partir de um acordo de integração; o que poderia consolidar sua posição negociadora com terceiros Estados e sua projeção no contexto regional. A harmonização das relações de Brasil e Argentina já se apresentava como um fator relevante para o estilo de inserção externa que a política exterior brasileira defendia.

A percepção do processo de integração, porém, não chegou a superar os limites do que uma perspectiva realista (típica da diplomacia brasileira) entenderia por soberania nacional. A diplomacia brasileira buscou sempre evitar que o arranjo de integração viesse a significar uma soberania partilhada no que se refere ao comportamento com outros parceiros externos. Os espaços de atuação externa do Brasil em termos individuais - relações bilaterais, negociações multilaterais e atuação em foros internacionais - não deveriam ser obstacularizados.

Desta forma, em termos institucionais o Mercosul respondeu às preocupações da diplomacia brasileira no que se refere à manutenção da soberania. As instituições estruturadas desde o Tratado de Assunção tiveram um caráter estritamente intergovernamental e não fizeram referência à política exterior, deixando assim livres os parceiros para atuarem por sua conta.

Apesar das diferenças mencionadas, no âmbito regional houve esforços de unificação de posições com a Argentina, em relação a temas que, até então, não eram consensuais, como parte de um processo de aproximação dos comportamentos na esfera regional. Os principais casos foram de posições assumidas em foros como o Grupo do Rio e a Organização dos Estados Americanos no que se refere, por exemplo, à questão cubana (embora com resultados, às vezes, de malabarismo diplomático). O grupo Garante da pacificação do conflito entre Peru e Equador contou também com a presença de ambos países.

No âmbito interno ao Mercosul, a defesa da democracia assumiu um papel importante, materializado na crise vivida pelo governo paraguaio, em 1996. Outros setores onde houve coincidências, já assinalados, foram a política nuclear e manobras militares.

Por fim, em outras questões de caráter regional, o Brasil buscou uma maior articulação com os países da região. As ações da diplomacia brasileira no Grupo do Rio e nas Cúpulas Iberoamericanas (embora estas com a presença também da Espanha e de Portugal) foram importantes, assim como a aproximação do Chile e da Bolívia do Mercosul. Em relação à fronteira norte, a chancelaria buscou estreitar os contatos com os vizinhos amazônicos, em particular no tocante aos problemas da Colômbia. 


\section{Conclusão}

A análise apresentada demonstra que as políticas externas do Brasil e da Argentina experimentaram grandes transformações nos anos 90 como conseqüência de crises domésticas e do colapso da Guerra Fria. A política exterior argentina foi redesenhada de acordo com o estabelecimento de um novo modelo de desenvolvimento depois da crise do final dos anos 80 , adotando uma nova postura frente aos grandes temas da política internacional. Graças à longevidade do governo de Carlos Menem (1989-1999), a nova política exterior teve uma grande continuidade durante o período. As mudanças bruscas do início da década marcam uma forte diferença em relação ao Brasil. Em primeiro lugar, a crise doméstica argentina apresentou-se como mais caótica que a crise brasileira. Em segundo lugar, a política externa brasileira não necessitava de grandes gestos por haver evitado, no passado, uma política de grandes confrontações. Finalmente, o corpo diplomático argentino não havia conseguido o grau de autonomia do Itamaraty e, portanto, era muito mais permeável e flexível frente às mudanças de política. Apesar de Ter havido resistências a certas políticas e gestos, em termos gerais o corpo diplomático acomodou-se rapidamente às transformações de políticas e idéias.

No caso do Brasil, a política externa experimentou transformações importantes como resposta às mudanças ocorridas na ordem internacional e no cenário doméstico. No entanto, estas transformações não se deram de forma linear. A própria trajetória interna de avanços e recuos nas reformas econômicas, assim como o forte predomínio da chancelaria e suas tradições no processo de formulação da política externa, contribuíram para que o processo fosse mais lento. A ascensão de Collor esteve acompanhada da denominada crise de paradigma que pôs em xeque os princípios da política externa anterior, mas não foi capaz de consolidar um novo conjunto de princípios. O governo de Collor foi seguido pela administração mais nacionalista de Franco, e dentro da chancelaria também conviveram estas duas visões.

Portanto, a estrutura das corporações diplomáticas como também o grau de continuidade dos governos, ajudam a entender o processo de transformação nas políticas externas de ambos países. Estes dois elementos explicam as diferenças nos processos de mudança e ajudam a descobrir a lógica das semelhanças. A diferença mais importante foi que a Argentina implementou mudanças profundas e abruptas no que se refere também às idéias que embasavam a formulação da política externa, enquanto o Brasil - devido às mudanças de governo, à autonomia do Itamaraty e a uma situação menos crítica que a Argentina - sofreu avanços e recuos que resultaram em um processo gradual de transformações no padrão de política exterior, combinando conceitos tradicionais com novas perspectivas. ${ }^{30} \mathrm{~A}$ semelhança mais destacável é que ambos implementaram modificações nas linhas gerais de sua política exterior no sentido de maior coincidência com regimes 
internacionais. Em termos específicos, a política nuclear e a adesão ao MTCR são exemplos relevantes de coincidência.

Dentre as diferenças a serem destacadas, a mais importante está relacionada à percepção que os decisores de política externa desenvolveram do lugar que o seu país tem no mundo. Enquanto o governo argentino destroçou a percepção tradicional que reservava um lugar de privilégio para a Argentina na América Latina e em suas relações com a Europa, os Estados Unidos e o mundo (seja como parceiro privilegiado ou como feroz opositor), o governo brasileiro manteve a posição que sustenta que o Brasil ocupa um lugar especial em termos político-estratégicos.

Em relação aos Estados Unidos, a percepção do governo argentino concebia o mundo sob o predomínio nítido de uma potência que, portanto, deveria ser o aliado fundamental. A visão da diplomacia brasileira foi organizada a partir do conceito das "polaridades indefinidas" do período de Itamar Franco até a idéia que defende que a principal potência - os Estados Unidos - buscaria adaptar-se às necessidades dos parceiros de maior relevância, e de outros menores, entre os quais encontrava-se Brasil.

Estas diferentes percepções tiveram como resultado uma modificação na política externa argentina, pautada pela relação que o governo gostaria de estabelecer com os Estados Unidos, enquanto o Brasil não parecia Ter um eixo tão claro em suas mudanças. A Argentina relacionou a grande maioria dos temas de política externa com os Estados Unidos. As mudanças no Brasil estiveram mais relacionadas às estratégias domésticas. Ademais, enquanto o governo argentino redefiniu radicalmente conceitos como soberania e interesse nacional relacionandoos aos objetivos econômicos domésticos, os governos brasileiros foram mais cautelosos na redefinição das idéias.

A política econômica jogou um papel crucial no desenho da política externa de ambos os países. A continuidade do Plano de Convertibilidade e a abertura econômica argentina ajudaram a estabelecer mais claramente as relações econômicas externas. No Brasil, a tensão entre os defensores de um neoliberalismo mais puro e os que resistiam a uma inserção nacional de caráter aberturista, que marcou a trajetória das políticas econômicas do período, levou o país a Ter relações econômicas externas mais incertas. Esta diferença é fundamental para se entender os avanços e retrocessos do processo de integração do Mercosul.

Sem dúvida, a transformação mais importante se dá nas relações entre ambos países. O re-desenho do papel interno das Forças Armadas, da política econômica e da política nuclear, e da visão estratégica são os elementos-chave para se entender o nascimento de uma relação de cooperação entre os dois, até então, rivais. Em termos econômicos, no tocante à integração regional, existem mais coincidências que em suas abordagens de temas de política internacional. 
Durante os anos 90, as políticas externas tanto argentina quanto brasileira experimentaram modificações, mas viveram mais distância do que proximidade entre elas. Suas diferenças, que o artigo buscou ressaltar, foram resultantes de fatores internos e de distintas percepções da ordem internacional por parte das respectivas diplomacias. Com a ascensão de Fernando Henrique Cardoso houve uma relativa aproximação das visões dominantes do novo ordenamento internacional, embora mantendo estilos e graus de autonomia distintos Depois desta década de transformações, o cenário atual de políticas exteriores encontra-se em uma etapa de indefinição. Se no caso brasileiro as posições vigentes estão mais consolidadas, no caso argentino a ascensão de Fernando de la Rúa à presidência sugere modificações na política externa, sem um regresso, contudo, ao paradigma dos anos 80 do último governo radical. Urgida por problemas internos, a nova administração ainda não definiu um perfil claro em matéria exterior.

Agosto de 2001

\section{Notas}

1 Sobre o papel da dimensão cognitiva na análise de política externa, Silva (1998a) é um artigo interessante.

2 Sobre as mudanças nas politicas externas latino-americanas no período, ver Cervo (2000a).

3 Sobre os processos de integração regional neste período, ver Saraiva (1999).

4 Sobre a crise do Estado na Argentina, ver Tedesco (1999).

5 Arbilla (2000) fornece elementos para se entender a lógica da formulação da política externa argentina.

6 Arbilla (2000), citando Roberto Russell (1990), Política Exterior y Toma de Decisiones en América Latina, Buenos Aires, GEL.

7 Carlos Escudé foi assessor do chanceler Di Tella e suas idéias sobre o realismo periférico correspondiam e davam base conceitual à percepção do chanceler da estratégia externa a ser seguida pela Argentina.

8 Cervo (2000b:52) chama a atenção aos esforços da Argentina de apresentar-se de acordo com a visão norte-americana da realidade internacional.

9 Lafer (1997:257) assinala para um substrato próprio da política externa que reflete a sociedade e suas experiências históricas e comenta a opção ocidental da Argentina.

10 Ver, por exemplo, Ambito Financiero (9/8/90:16; 31/12/9:14; 3/8/94:20), Clarín (2/5/93:2; 13/3/ 94:15; 9/12/94:15; 12/1/95:23;23/6/94:12-13), e La Nación (18/6/95:8).

11 Lafer (1977:259) ressalta que, apesar da reincidência destes comentários Nafta/Mercosul, apenas 8,64\% das exportações argentinas dirigiam-se para os Estados Unidos, enquanto 32\% orientamse para o Mercosul.

12 O comércio passou de 3,0 bilhões de dólares (FOB) em 1991 para 14,8 em 1998. Cervo (2000b).

13 Os sócios do Chile haviam sido Suíça e Reino Unido.

14 Os carapintadas organizaram quatro rebeliões militares entre 1987 e 1990 . Seu maior objetivo era terminar com os julgamentos pelas violações dos direitos humanos.

15 Sobre a questão da corporação diplomática e sua relação com a classe política e os setores sociais, ver Lima e Hirst (1994), e Lima (2000).

16 Sobre la cuestión del discurso diplomático do período, pode-se ver o artigo de Silva (1999). 
17 Sobre a política externa dos governos de Collor e Itamar Franco, Hirst e Pinheiro (1995) proporcionam um quadro importante de consulta proveitosa para qualquer pesquisa sobre o período.

18 Em relação à percepção da diplomacia brasileira da ordem internacional pós-1990, o paper de Silva (1998b) coloca uma discussão interesante.

19 Lima e Hirst (1994:59) indicam as áreas de interesse de ambos lados: temas econômicos por parte do Brasil e democracia, meio ambiente, tráfico de drogas, e direitos humanos, por parte dos Estados Unidos.

20 Luiz Felipe Lampreia (chanceler do governo de Cardoso) sustentou: "Acabaram-se os tempos de isolacinesimo e auto-suficiência. A soberania nacional deixou de ser argumento para comportamentos que atentam contra os valores fundamentais"; "A autonomia pela integração significa apoio aos regimes internacionais". Lampreia (1998:8:11).

21 Pinheiro (2000) levanta um discussão interessante sobre a política externa brasileira atual apontando para o institucionalismo pragmático como norteador do comportamento externo da diplomacia.

22 O texto de Fonseca Jr. (1999) - representante atual do Brasil nas Naçõess Unidas- contribui enormemente a se entender a percepção da diplomacia brasileira.

23 Ver Amorim (1995) e Abdenur (1994). Ambos são diplomatas de primeira linha tendo sido o primeiro chanceler do governo de Franco. Sobre a percepção brasileira do "lugar devido" entre os grandes, ver Silva (1998b).

24 Ver na Folha de São Paulo (25/6/95:1-3) a defesa da reforma do Conselho de Segurança da ONU em relação a sua eficácia baseada na representatividade e legitimidade onde Brasil deveria ter um assento permanente; e no Jornal do Brasil (6/10/2000:11) onde Cardoso ressalta a candidatura brasileira.

25 Argentina participou entre 1988 e 1997 de 17 Operações com observadores ou efetivos, enquanto Brasil participou de 9, e com efetivos apenas nos casos de Angola e Moçambique. Em 1998 se apresentou, como já assinalamos, una diferença no caso do Haití, quando a Argentina apoiou e Brasil se absteve (junto à China) de apoiar o envio da força multinacional.

26 Sobre a política externa brasileira e o Mercosul, ver Saraiva (1996).

27 A partir de negociações coletivas foi firmado um Acordo Marco com a União Européia e Acordos de Livre Comércio com o Chile e a Bolívia.

28 A subordinação às "ditaduras das conjunturas econômicas" foi assinalada por Pedro Motta Veiga em mesa redonda que teve lugar na Fundação Getúlio Vargas/CPDoc, setembro de 1995.

29 As diferenças e conflitos entre as diplomacias e agentes econômicos dos dois países por divergências em política cambial, política de investimentos e setores específicos de importação/ exportação são um marco constante nas relações, agravado sobretudo depois da desvalorização do Real no início de 1999.

30 Esta discussão pode ser vista em Arbilla (2000).

\section{Bibliografía}

ABDENUR, Roberto (1994).A política externa brasileira e o "sentimento de exclusão". In: Gélson Fonseca Jr e Sérgio Henrique Nabuco de Castro (org.), Temas de Política Externa Brasileira volume I. São Paulo, Paz e Terra.p. 31-46.

ÁMBITO FINANCIERO, vários números.

AMORIM, Celso (1995). O Brasil e o Conselho de Segurança das Nações Unidas. Politica Externa vol.3 n.4. São Paulo, maio.p. 3-15. 
ARBILLA, José María (2000). Arranjos Institucionais e Mudança Conceitual nas Políticas Externas Argentina e Brasileira. Contexto Internacional vol.22 n.2. Rio de Janeiro, IRI-PUC/RJ, jul./dez. p.337-385.

CERVO, Amado Luiz (1998). Multilateralismo e integración: evolución del pensamiento diplomático brasileño. Ciclos Año VIII n.14-15. Buenos Aires, IIHES/UBA, 1er. semestre. p.205-226.

CERVO, Amado Luiz (2000a). Sob o signo neoliberal: as relações internacionais da América Latina. Revista Brasileira de Política Internacional Ano 43 n.2. Brasília, IBRI. p.5-27.

CERVO, Amado Luiz (2000b). A política exterior da Argentina: 1945-2000. In: Samuel. Pinheiro .Guimarães (org.) Argentina: visões brasileiras. Brasília, IPRI/Funag,

CHOMSKY, Noam (1992). Deterring Democracy. Londres: Vintage.

CLARÍN, vários números.

DHARENDORF, Ralf (1995). La cuadratura del circulo. México: Fondo de Cultura Económica.

ESCUDÉ, Carlos (1995). El realismo de los estados débiles. Buenos Aires: Grupo Editor Latinoamericano.

ESCUDÉ, Carlos e Fontana, Andrés (1996). Argentina's Security Policies. Their Rationale and Regional Context. In: Domínguez, J. (ed.), International Security and Democracy, University of Pittsburgh Press.

FOLHA DE SAO PAULO, 25/6/1995.

FONSERCA JR, Gelson (1999). Anotações sobre as condições do sistema internacional no limiar do século XIX: a distribuição dos pólos de poder e a inserção internacional do Brasil. In: G.Dupas e T.Vigevani (org.), O Brasil e as novas dimensões da segurança internacional. São Paulo, AlfaOmega/Fapesp. p.17-42.

HIRST, Mónica e Pinheiro, Leticia (1995). A política externa do Brasil em dois tempos. Revista Brasileira de Política Internacional Ano 38 n.1. Brasília, Ibri. p.5 -23.

JORNAL DO BRASIL, 12/6/1998 e 6/10/2000.

LA NACIÓN, vários números.

LAFER, Celso (1997). Relações Brasil-argentina: Alcance e Significado de uma Parceria Estratégica. Contexto Internacional vol.19 n.2. Rio de Janeiro, IRI-PUC/RJ, jul./dez. p.249-265.

LAFER, Celso e Fonseca, Jr (1994). Questões para a Diplomacia no Contexto Internacional de Polaridades Indefinidas. In: G.Fonseca Jr. e S.H.Nabuco de Castro (org.), Temas de Política Externa Brasileira II, vol. I. São Paulo, Paz e Terra/Ipri. p. 49-77.

LAMPREIA, Luiz Felipe (1998). A política exterior de Fernando Henrique Cardoso. Revista Brasileira de Política Internacional Ano 41 n.2. Brasília, Ibri. p.5-17.

LIMA, Maria Regina Soares de (2000). Instituições Democráticas e Política Exterior. Contexto Internacional vol.22 n.2. Rio de Janeiro, IRI-PUC/RJ, jul./dez. p.265-303.

LIMA, Maria Regina Soares de e Hirst, Mónica (1994) .O Brasil e os Estados Unidos: dilemas e desafios de uma relação complexa. In: Fonseca Jr. e Nabuco de Castro (org.), Temas de Política Externa Brasileira I- V.2. São Paulo, Paz e Terra. p.43-64.

PINHEIRO, Letícia. Traídos pelo Desejo: um ensaio sobre a teoria e a prática da política externa brasileira contemporânea. Contexto Internacional vol.22 n.2. Rio de Janeiro, IRI-PUC/RJ, jul./ dez. p.305-334.

RESENHA DE POLÍTICA EXTERIOR DO BRASIL, n.75, jul./dez.1994, p.15.

ROSECRANCE, Richard (1986). The rise of the trading state. New York: Basic Books.

SARAIVA, Miriam Gomes (1996). El Mercosur como una prioridad de la política exterior brasileña. América Latina Hoy, segunda época n.14. Madrid, Sepla, octubre. p.55-59.

SARAIVA, Miriam Gomes (1999). Os processos de integração latino-americanos e europeu. As experiências dos anos 60 e o modelo de integração com abertura econômica dos anos 90 . Revista Internacional de Estudos Políticos vol.1 n.1. Rio de Janeiro, Nuseg/Uerj, abril. p.167-190.

SARAIVA, Miriam Gomes (2000). Brasil e Argentina: uma década de política externa. Cena Internacional Ano 2 n.1. Brasília : Rel-UNB/Funag, jun./2000. p.5-17. 
SCHIRM, Stefan (1996). Globalização transnacional e Cooperação regional na Europa e na América Latina. Contexto Internacional vol.18 n.2. Rio de Janeiro, IRI-PUC/RJ, jul./dez. p..257-290.

SILVA, Alexandra de Mello e (1998a). Idéias e política externa: a atuação brasileira na Liga das Nações e na ONU. Revista Brasileira de Politica Internacional Ano 41 n.2. Brasília, Ibri, p.139-158.

SILVA, Alexandra de Mello e (1998b). O retorno do "destino manifesto": o Brasil face à reforma do Conselho de Segurança da ONU. Caxambú. Apresentado no 22do Encontro Anual de Anpocs, outubro.

SILVA, Alexandra de Mello e (1999). A política externa em transição: rumo a um novo paradigma? Net Work vol.8 n.3. Rio de janeiro, CEA's/Ucam, jul./set. p. 6.

TEDESCO, Laura (1999). Democracy in Argentina: Hope and Disillusion. Londres: Frank Cass.

TEDESCO, L. (2000) La ñata contra el vidrio: urban violence and democratic governability in Argentina. Bulletin of Latin American Research 19 (4). p. 527-545.

TULCHIN, Joseph (1998). Continuity and Change in Argentina Foreign Policy. In J.Tulchin and A.Garland (eds.) Argentina: the Challenges of Modernization. Wilmintgton: Scholarly Resources Inc. p.163-197.

\section{Resumo}

O artigo analisa as mudanças nas políticas exteriores de Argentina e Brasil depois da Guerra Fria. É um estudo comparativo das linhas gerais de suas políticas externas nos anos 90, com ênfase na percepção, respectiva, da nova ordem internacional. Neste marco, trabalha com as relações com os Estados Unidos, as questões de segurança e as relações regionais. Conclui examinando as diferenças e semelhanças que marcam estas políticas, analisando a influência exercida tanto pela ordem internacional quanto a nível interno sobre suas respectivas reformulações.

\section{Abstract}

This article examines the foreign policy of Argentina and Brazil after the end of the Cold War. It is a comparative study of the main trends in foreign policy, emphasising each country's perception of the new world order. In this context, the article discusses the relation with the United States, regional relations and security issues. It concludes by analysing the differences and similarities which characterise the 1990s foreign policies in both countries, pointing out the impact that the transformation of the international order has had in the re-shaping of the policies.

Palavras-chave: Política Externa Brasileira, Política Externa Argentina, Ordem Internacional.

Key-words: Brazilian Foreign Policy. Argentina Foreign Policy. International Order. 